\title{
Extended strategy-use instruction to improve students' reading proficiency in a content subject
}

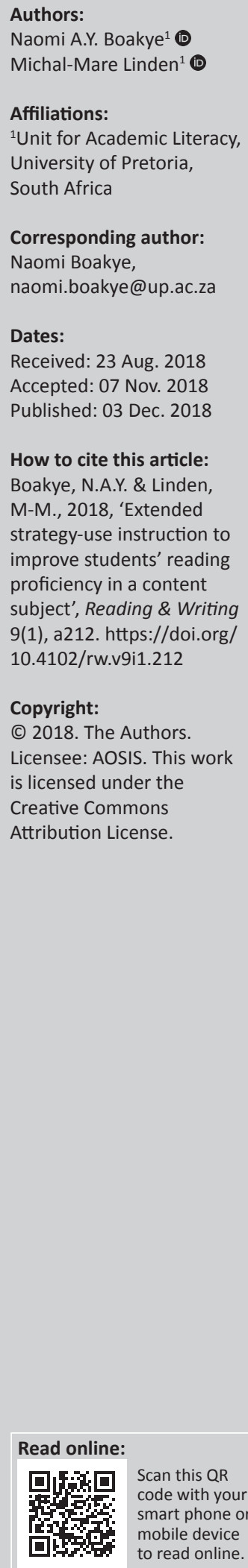

Background: Student reading challenges have been reported worldwide. In many classrooms around the world, teaching students appropriate strategy-use has been a technique used to improve comprehension and improve reading proficiency. However, strategy-use instruction per se may not produce holistic results.

Objectives: This article reports on an extended strategy-use instruction to improve students' reading proficiency in a particular subject area. The technique of role-play, as well as an integration of affective strategies, was used to improve the cohort of first-year students' reading of subject-specific texts.

Method: The intervention was conducted by way of tutorials. A questionnaire was used to elicit students' views and opinions after the intervention. The responses were analysed using content analysis of emerging themes.

Results: Students reported benefiting from the intervention with respect to reading their assigned texts, as well as increased motivation.

Conclusion: It is recommended that strategy-use instruction include other innovative techniques such as role-play to improve students' reading proficiency in a specific subject.

\section{Introduction}

An issue of concern in the South African education system is the low literacy levels of learners. Reading is of great importance in education, and in particular, in academic performance. Failure to develop reading proficiency at school level impacts heavily on academic performance at tertiary level (Pretorius 2002). According to Boakye (2011), reading challenges become glaringly evident at tertiary level, especially in the case of students who are not learning in their home language and have been disadvantaged by various socio-economic issues in South Africa, such as the legacy of apartheid, inequality in education and poverty. Reading challenges hinder these students' successful academic performance, especially in disciplines such as sociology where students are required to do large volumes of reading as part of their coursework.

Sociology is, however, not unique in this respect; many modules at university level have the same requirement with regard to the volume of reading. The texts can be lengthy and may contain complex and technical vocabulary (Roberts \& Roberts 2008:131). At first-year level, students are usually introduced to texts by sociologists such as Emile Durkheim, Max Weber and Karl Marx, all of which may seem inaccessible to students who are unable to read independently. Roberts and Roberts (2008:126-127) noted that sociology students tend not to do their prescribed reading because of the extent and complexity of the texts. These authors claim that avoiding reading course material prevents students from contributing in class discussions, and consequently, they underperform in the module. A similar trend was found by Boakye (2017a) at the University of Pretoria, South Africa, where the current study was conducted. The author found that majority of first-year sociology students do not read their assigned texts. These students were experiencing reading challenges, which led to poor reading or failure to read texts. Consequently high failure rates were recorded for the module (University of Pretoria Department of Sociology 2014). Although introducing compulsory tutorials reduced the failure rate, a number of students continued to complain about reading challenges (Boakye 2017a). Anecdotal evidence gathered from discussions with lecturers and tutors in the Department of Sociology confirmed that reading challenges and a lack of reader engagement with texts were some of the major factors contributing to the high rate of failure.

In view of this ongoing concern, a reading intervention was undertaken with these first-year students. The intervention sought to introduce the students to a variety of reading strategies 
in order to improve their reading comprehension and critical reading abilities. In addition, it sought to highlight the affective dimension of reading in order to help students form personal connections to the texts they read and to their study materials in general, as well as improve their affective reading levels.

The aim of this study was to investigate the efficacy of this reading intervention with respect to first-year sociology students at the University of Pretoria, South Africa.

\section{Literature review}

\section{Reading literacy}

A number of South African reading researchers have argued that students' poor reading ability at tertiary level is a direct result of poor reading ability at school level (Howie et al. 2017; Pretorius 2007; Pretorius \& Lephalala 2011; Taylor \& Yu 2009; Van Staden \& Bosker 2014; Zimmerman 2014). Studies on the teaching of reading literacy in South African primary schools reveal a number of gaps, such as low exposure to texts and poor reading instruction. For example, Van Staden and Bosker $(2014: 5,8)$ point out that reading skills are introduced to learners too late at school, and little time is spent on reading instruction. She reports that the majority of Grade 4 teachers surveyed across the curriculum spent less than 2 hours on reading. Zimmerman (2014:7), in her observations of the teaching of reading comprehension in Grade 4 in a number of South African schools, found that the teaching of reading literacy is poor during the Foundation Phase at primary school. By the time they reach Grade 4, learners have a reading comprehension backlog accumulated over previous years of schooling, and as a result Grade 4 teachers have to teach at a slower pace and a lower level. Of even more concern is that Zimmerman (2014) found a number of teachers lacking the skills required to teach reading literacy, and particularly comprehension. Consequently students are inadequately prepared to read and comprehend texts independently (Zimmerman 2014:7). Zimmerman and Smit (2014) note similar trends in their studies and express particular concern about teachers' poor understanding of teaching reading comprehension. In other words, they posit that a number of South African teachers do not succeed in generating the ability to comprehend reading material beyond information retrieval and do not encourage written responses (Zimmerman \& Smit 2014:6). They also noted in their observation that successful teachers had declarative knowledge of teaching reading comprehension skills and utilised theoretical models of comprehension and a variety of reading comprehension strategies as needed in response to students' needs (Zimmerman \& Smit 2014:6).

Pretorius and Klapwijk (2016) explored the literacy practices of teachers in rural and disadvantaged areas and found they did not include appropriate reading strategies. This was confirmed by Boakye's (2017a) study. Her survey showed that the majority of first-year sociology students stated that reading did not receive much attention in their schools, and instruction was for a limited time and given haphazardly.
The students further confirmed that deep engagement with texts was not required at school level and they found a huge gap between reading at tertiary level and reading at school level (Boakye 2017a). Unfortunately, very little is done at tertiary level to bridge this reading gap. As Roberts and Roberts (2008) have noted, sociologists expect their students to be able to read, and do not take into consideration inadequacies or challenges students may be facing because of inadequate teaching at school.

At tertiary level, there has been limited research on the state of students' academic reading ability. However, reading challenges are experienced by students all over the world. Bean (2011) identifies 11 reasons for students' reading difficulties, such as schools (and the academy) that reward surface reading; lecturers' teaching of reading material, rather than encouraging students to work independently; students' difficulty in engaging with unfamiliar ideas; students' inability to critically digest the argument of a text; students' inability to understand and engage with the text; students' resistance to spending time on deep reading; students' difficulty with syntax and vocabulary; students' inability to adjust their reading strategy according to the text's genre; and lecturers' and authors' assumptions that students have access to 'cultural literacy'. These issues result in a lack of 'deep reading', which involves conscious engagement with a text for learning and enjoyment purposes (Bean 2011:166). It also means that students do not internalise a text, an activity that Roberts and Roberts (2008) highlight as a mark of efficient reading.

Pretorius' $(2000,2002)$ research, which focused on psychology and sociology students at tertiary level, suggested that students' reading ability was in decline then, inter alia because of historical and socio-economic issues (2000:45). It seems after more than 10 years, it is still in decline (Boakye 2012). She (2000:43, 2002:169) contends that low reading literacy levels are predominant among L2 learners as a result of their poor inferencing and comprehension skills, which are essential for understanding texts and engaging with them. Because of these low reading literacy levels, a number of these students find it difficult to produce accurate or detailed representations of complex psychology or sociology texts (2000:45). Pretorius (2000:46). concludes that a lack of interventions allows these problems to persist, giving rise to a cycle of failure. In response, the current study seeks to provide ways of addressing these challenges by means of integrated strategies and to contribute to the limited body of research on reading at tertiary level.

\section{Reading strategies}

Literature investigating the state of reading literacy in South African schools as well as the limited studies at tertiary level seem to indicate reading strategies as a focal point. According to Hosseini et al. (2012:1357), if the end product of reading is comprehension, then reading strategies can be understood as the 'quintessence of successful comprehension ... at any level of processing'. Appropriate use of reading strategies is 
important, as it plays a crucial role in assisting students to comprehend the texts they read. Hosseini et al. (2012:1361) advocate for the necessity of applying reading strategies, as it has a positive effect on reading comprehension and critical thinking, especially among second language learners. In other words, utilising reading strategies helps to facilitate deep reading, deep thinking, well-rounded understanding and internalisation of texts (Hosseini et al. 2012:1361-1362).

While there have been several interventions to counteract the South African literacy crisis at school level, there has been limited response to how this crisis affects tertiary education studies and how it should be addressed. Boakye (2017a) suggests a possible solution in terms of response theory. In her presentation of a multifaceted model for designing reading development programmes for L2 learners at tertiary level, she includes affective and social aspects (Boakye 2011). She points out that university students may not necessarily have the required literacy levels, especially if coming from disadvantaged backgrounds. As a result, they often struggle to cope with required reading (Boakye 2011:111). As a possible solution to this dilemma, she argues for literacy interventions that utilise an affective dimension in reading literacy instruction. This approach, she explains, encourages reader engagement through a focus on 'motivation, attitude, interest, and self-efficacy' (Boakye 2011:111). In addition, Guthrie and Wigfield (2000) argue for engaged reading as, according to them, it can compensate for the effects of 'low family income and poor educational background'. In their engagement model, Guthrie and Wigfield (2000) posit that deep reading and better comprehension of texts can be achieved through engagement, which can be obtained through integrated reading instruction. Boakye (2011:117) adapts the model to the South African context and argues for a socio-affective approach to reading intervention. Her intervention with first-year tertiary students in an academic literacy module was shown to improve students' affective reading levels, particularly the aspect of interest, motivation to read and deeper engagement with texts (Boakye 2017b:14). In addition, the intervention boosted the self-confidence of students in weak reading groups, which increased their motivation to read (Boakye 2017b:15). Thus, both high and low risk students were found to have improved in affective reading level and were motivated to read not only academic texts but also for pleasure. This points to the importance of reading interventions to be sensitive to socio-economic status and the affective dimension in reading literacy instruction.

\section{Reading in a subject field}

In relation to reading texts in a specific subject, Roberts and Roberts (2008) investigated deep reading among sociology students and found that the majority of students do not engage in deep reading and neglect to read their course material. They highlight reasons why sociology students neglect to read their course material, and propose a possible solution to students' apathy towards course literature. They (2008:125) argue that university students fail to read for understanding because high school education encourages regurgitation of information, rather than requiring students to find personal relevance in a text. According to Bloom's taxonomy, memorising information is the least complex educational learning objective (Anderson et al. 2001). Education that focuses on retention of information results in 'surface learning based in episodic memory or short-term memorisation for a day or two, rather than deep learning that is transformative of one's perspective and involves long-term comprehension' (Roberts \& Roberts 2008:127). This superficial reading is further encouraged by the academy that offers rewards for basic memorisation, further fostering a 'simplistic cost/benefit process' that most often results in students doing the minimum reading for the maximum output (Roberts \& Roberts 2008:129). The authors note that while content quizzes have been suggested as a remedy for this issue, quizzes are time-consuming and 'reinforce the rational choice approach that is part of the problem' (Roberts \& Roberts 2008:130). These issues are particularly true for the first-year sociology students who are the subjects of this study.

In view of the issues discussed above, Roberts and Roberts advocate for the use of 'reading responses'. This method requires students to read a text and summarise it or respond to it in one of several ways (Roberts \& Roberts 2008:131-132). The various forms that a reading response can take are drawn from Howard Gardner's forms of multiple intelligences in relation to Bloom's more complex educational objectives. Students were assessed on their reading responses weekly while their examinations targeted 'big ideas, analysis, synthesis, [and] evaluation' (Roberts \& Roberts 2008:133). Results from the study showed that the sociology students read more of their coursework and actually read with purpose (Roberts \& Roberts 2008:134). While reading responses offer a short-term reward, they introduce students to reading strategies that will hopefully shift the focus away from an emphasis on achieving grades to 'reading for the sake of learning from it' (Roberts \& Roberts 2008:134). This shift in focus can perhaps be achieved because reading responses aim to incorporate an affective dimension into reading by allowing students to work in modes with which they are comfortable, such as music and visuals. While this study is relevant and achieved success, the model may not fit seamlessly into the South African context, which comprises learners from different educational and social backgrounds who possess varying competencies.

Another intervention of similar approach was conducted by Parrott and Cherry (2011) using structured reading groups to facilitate deep learning (2011). Parrott and Cherry (2011:354) acknowledge the difficulty in getting sociology students to engage in deep reading of their coursework texts. However, they propose a slightly different approach, which assigns students to 'reading groups', each of which has a different, rotating role: discussion leader, passage master, devil's advocate, creative connector and reporter (Parrott \& Cherry 2011:354). The groups meet throughout the semester, and before each meeting students must complete a number of readings and then prepare for the role they have been assigned (Parrott \& Cherry 2011:354). The strategy has two 
underlying ideas: firstly, to encourage students to commit to deep reading, and secondly, to use the information they have engaged with for a particular purpose, such as discussing hot topics' (Parrott \& Cherry 2011:354-355). In studying the efficacy of these reading groups, Parrott and Cherry (2011:360) found the method not only popular among students, but it also increased the likelihood of students reading course material, helped them to understand the texts and helped them to make connections between the information and everyday life (Parrott \& Cherry 2011:361). In other words, the reading groups helped students achieve the course outcomes of 'developing a deep understanding of course material, using course concepts to better understand social processes, and being able to use class information to discuss current social issues' (Parrott \& Cherry 2011:354-355). The reading groups also fostered a sense of accountability that motivated students to do their readings, as not doing so would mean letting the group down (Parrott \& Cherry 2011:361). The authors also argue that this method improves upon the method previously proposed by Roberts and Roberts (2008) in that the work is done not individually but also in groups, which teaches teamwork skills (Parrott \& Cherry 2011:355). A similar method was employed in this study.

\section{Affective factors in reading}

These teaching techniques highlight the affective aspects of reading as a means of improving students' reading comprehension. According to Grabe and Stoller (2011), the affective dimension is pertinent to reading comprehension as it contributes to students' willingness to read frequently and to become involved in their reading. The affective factors focused on in this study are motivation, self-efficacy, attitude and interest.

Motivation is defined as 'the individual's personal goals, values, and beliefs with regard to the topics, processes, and outcomes of reading' (Guthrie \& Wigfield 2000:405). In order to increase students' motivation, they were required to read and share their understanding, taking on different roles. Bandura (1986:391) describes self-efficacy as 'people's judgements of their capabilities to organise and execute' various actions in order to achieve certain goals. Thus, students' self-efficacy can be understood as how they view themselves as readers: whether they believe they are competent and successful readers or not. Students' selfefficacy levels were targeted through scaffolding of the texts to be read, as well as discussions that took place in small groups among peers where students felt comfortable to share their views.

Attitude can be perceived as 'a sense of "liking" or a continuum with positive and negative extremes' (McKenna 2001:147). McKenna (2001:147) suggests there are two parts to reading attitude, namely attitude towards reading for pleasure and attitude towards reading of academic texts. The intervention sought to instil a positive attitude towards reading of academic texts. While interest relates to two forms of curiosity, namely personal and situational, personal interest is perceived as internal and is the 'enduring attraction to a topic even before a particular text is read' (Boakye 2017b; Hidi \& Anderson 1992:216; Schiefele, Krapp \& Winteler 1992:152). Situational interest, on the other hand, is 'short-lived emotional states' drawn from a particular context (Hidi \& Anderson 1992:216). Interest therefore differs from attitude and motivation, as it does not rely on particular goals or past experiences to be present in an individual (Hidi \& Anderson 1992:216). In order to develop students' interest, texts were subjected to lively discussion and connections were drawn between texts and students' personal and everyday life issues.

Boakye (2017b:4) posits that by giving attention to these affective factors students develop the desire to read. They are able to form personal connections with the texts and enjoy reading. The cognitive outcome of the development of affective reading is the application of appropriate reading strategies, which leads to efficient reading and deeper comprehension (Boakye 2017b:4; Grabe \& Stoller 2011; Guthrie 2008). This is particularly important for non-native English speakers and students from low socio-economic backgrounds who, because of limited exposure to reading materials, have low reading literacy levels and consequently become easily frustrated while reading, which causes them to develop negative attitudes towards reading (Pretorius 2000).

In view of the issues discussed and reading challenges of students at tertiary level, as well as the limited research on reading at tertiary level, an intervention was undertaken with sociology students to improve their reading of sociology texts, using the cognitive strategies in Parrott and Cherry (2011), integrated with affective strategies.

The aim of the study was to assess the effect of innovatively combining cognitive and affective strategies through tutorials with a view to improving students' reading of sociology texts.

The following research questions were posed for the study:

- What are students' opinions of the intervention techniques (integrated use of strategies) used during tutorials to improve their reading ability?

- Do students' opinions of the intervention techniques used during tutorials indicate positive outcomes?

\section{Methodology Research design}

The methodology comprised both quantitative and qualitative analysis. Although data were collected through verbal means (open-ended questionnaire), the data were analysed using both qualitative and quantitative methods. Verbal data were analysed using content analysis to provide percentages, and specific examples were used to support the resulting percentages. The methodology therefore comprised both quantitative and qualitative analysis. According to Hsieh and Shannon (2005:1278), in conventional content analysis, verbal 
data can be coded into categories and then described using statistical analysis. They state that this approach is referred to by Morgan (1993) 'as quantitative analysis of qualitative data' (Hsieh \& Shannon 2005:1278). They point out that such a design would aim to describe a phenomenon, in which researchers would avoid using preconceived categories but rather allow categories to flow from the data.

\section{Participants}

The participants were first-year sociology students at the University of Pretoria. The students were registered for various programmes in different faculties. Only a limited number of students proceed to major in sociology; the majority take sociology as an ancillary subject at first-year level. Although they had lectures twice a week in a large group, they also had to attend a $1 \mathrm{~h}$ tutorial consisting of about 20-25 students once a week to discuss texts and topics taught during lectures. The tutorials were conducted by postgraduate students who had taken sociology as a major subject or obtained a high mark for their first-year sociology exam. A workshop was conducted to train tutors in the integrated instructional approach of the intervention. Although 425 students were registered for the first-year sociology module, only 254 completed the questionnaire. Other students may not have attended tutorials during the week of data collection or may have opted not to complete the questionnaire because it was voluntary.

\section{Intervention and research instrument}

The intervention was organised around prescribed texts. The first semester sociology course comprised readings on Emile Durkheim, Max Weber and Karl Marx. In previous years, tutors merely attempted to explain the texts to the students during tutorials. During the intervention, excerpts were taken from sections of these readings. Students were divided into groups, and the group leader had to assign a role to each member. The different roles were first explained by the tutor to the group as a whole. Depending on his or her assigned role, a student had to summarise the text in his or her own words, find meanings of unfamiliar words and concepts, or connect the text to everyday life issues. During tutorials, students engaged with the texts, with each member contributing according to his or her assigned role in a non-threatening environment. Each group then presented to the whole class, followed by a class discussion of the texts, with the tutor providing positive feedback to guide the students. The intervention lasted for 12 weeks and came to an end when the tutorial sessions for the semester ended. At the end of the intervention, students' opinions and experiences of the intervention were elicited by means of a questionnaire. The questionnaire consisted of a Likert scale section that focused on specific issues and an open-ended section that aimed to determine students' opinions on the intervention. The open-ended section, which is reported on in this article, required students to comment on and explain how the tutorials and the role-play reading activities influenced their: (1) reading of sociology texts; (2) understanding of concepts; (3) writing of sociology assignments; and (4) writing the sociology examination. They were also asked to provide any additional comments they wished to make regarding the intervention.

\section{Data collection and procedure}

During the first week of the second semester, the questionnaire was administered during tutorials to elicit students' opinions and experiences of the techniques used to facilitate comprehension of the texts during the first semester. Ethical requirements were complied with. In addition to obtaining ethical approval from the Faculty of Humanities, students were assured of anonymity. They were alerted to the fact that their participation was voluntary, and they had to sign an informed consent form to indicate their willingness to participate.

\section{Data analysis}

Students' verbal responses to the open-ended questions were analysed using emerging themes. The categories or themes therefore emerged from the data, as explained by Hsieh and Shannon (2005). The predominant themes were first identified and coded. They were then counted, calculated and presented as percentages to show their predominance.

Some questions were not answered by some of the students, so although there were 254 students the total number of answers for each question was different. For each question: (1) reading of sociology texts; (2) understanding of concepts; (3) writing of sociology assignments; and (4) writing the sociology examination - predominant themes were identified and counted. The total for each of the five emerging themes in each question was calculated as a percentage. In other words, the number of times a specific theme occurred was divided by the number of students who had answered that question and multiplied by one hundred. The major themes in the responses were identified as follows: (a) the techniques helped students to understand what they read, even difficult concepts; (b) the group discussions in particular were helpful; (c) the mind-map and role-play activities aided understanding; (d) students initially struggled with the assigned readings but the tutorial activities helped them overcome the challenges; (e) the intervention was not helpful; (f) students were still having difficulty with reading the texts. Question 5 required students to provide any other information they wished to add.

In presenting the findings, examples for each theme or category are provided from the data (Hsieh \& Shannon 2005:1279). Thus, in addition to the percentages, verbal examples are provided to shed more light on the predominant emergent themes.

\section{Ethical consideration}

Ethical clearance was applied for, and obtained from the Faculty of Humanities, University of Pretoria, South Africa. 


\section{Findings and discussion}

The results are presented below according to the questions ( 1 to 5 ) and the themes (a to f) that emerged under each question. A summary of the data showing the responses as percentages is provided in Table 1 . Thereafter, the responses showing the emergent themes for each question are presented in Figures 1-5.

From the results given in Table 1, it is clear that a large majority of students (Q1: 91\%; Q2: 90\%; Q3: 90\%; Q4: 93\%) experienced the intervention as positive and felt it assisted them with their sociology classwork. Less than $10 \%$ (i.e. $7 \%$ ) of the responses for Questions 1 to 4 were negative. The few students who gave negative responses indicated that the intervention was not helpful and that they were still experiencing reading challenges. Unfortunately for the fifth question, where students were to provide further information, a large number of students (more than $70 \%$ ) did not provide any information.

The responses to each question are presented graphically and discussed. Figures 1-5 show the responses as a percentage according to the emerging themes.

Although an overwhelming majority of students gave positive responses, there were a few negative responses. For example, in Question 1, only $4.12 \%$ of students indicated that they were still having difficulty with the reading of their texts; and $1.62 \%$ indicated that they did not find the intervention helpful. However, compared to the positive responses regarding the benefits of the intervention (91\%), the negative responses were very few and did not reflect the overall assessment of the intervention. Nevertheless, the fact that these responses were present calls for an investigation to determine what problem(s) this specific group of students could have. The few students $(2.88 \%)$ who did not find the intervention beneficial and who reported that they were still struggling with their assigned reading could be students who had done very little reading in their home language or in English. They may have come from low socio-economic backgrounds and may have attended poorly resourced schools where there was no focus on reading development. As a result, they may have had limited exposure to texts, which could have led to their still facing challenges in reading despite the intervention. A similar trend was found in the responses for all the questions. Responses that did not match any of these major trends were placed in the non-category classification. As indicated in the previous section, the answers to the five questions suggested that the intervention generally produced a positive outcome. The responses to the individual questions are discussed below.

In Question 1, students were asked to comment on and explain how the tutorials and role-play activities assisted them in their reading of sociology texts. The majority of students (91\%) reported that the tutorials helped them understand sociology concepts and the assigned readings. A quarter of the students reported that being taught reading strategies during tutorials was extremely helpful. Some students stated that the tutorials helped them to understand and use appropriate reading strategies, realise the benefit of summarising texts that they read and enabled them to relate

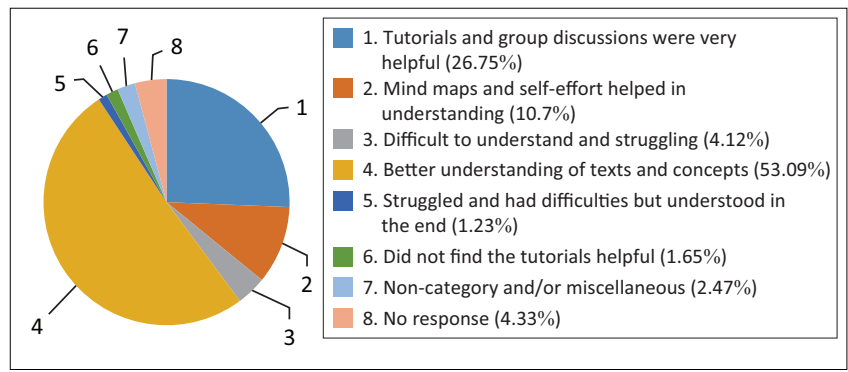

FIGURE 1: Student responses to Question 1 as percentages.

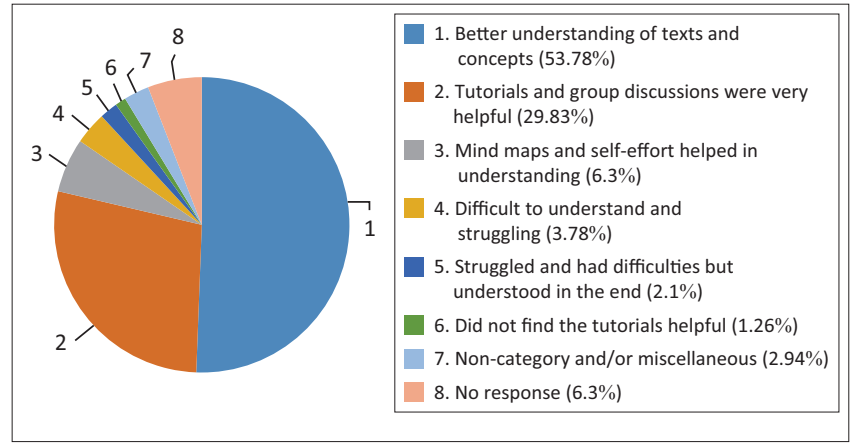

FIGURE 2: Student responses to Question 2 as percentages.

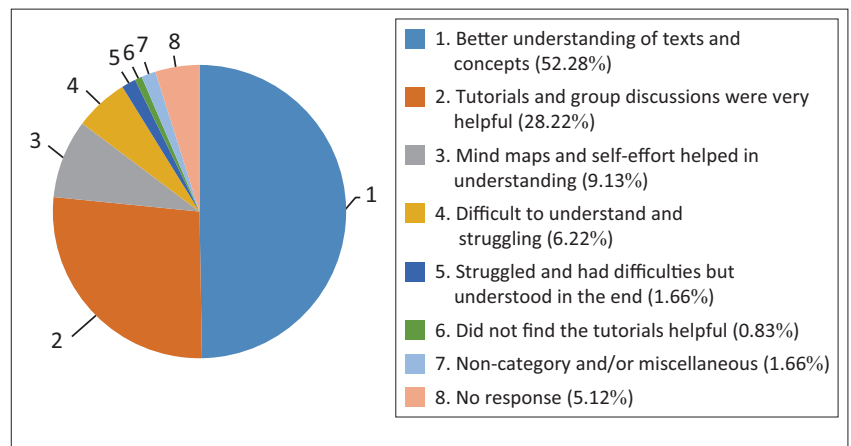

FIGURE 3: Student responses to Question 3 as percentages.

TABLE 1: Emergent themes and responses as percentage

\begin{tabular}{|c|c|c|c|c|c|c|c|c|c|c|}
\hline Questions & $\begin{array}{c}\text { Total } \\
\text { number of } \\
\text { students }\end{array}$ & $\begin{array}{c}\text { Total } \\
\text { number of } \\
\text { responses }\end{array}$ & $\begin{array}{c}\text { Better } \\
\text { understanding } \\
\text { of texts and } \\
\text { concepts } \%\end{array}$ & $\begin{array}{c}\text { Tutorials and group } \\
\text { discussions were } \\
\text { very helpful } \%\end{array}$ & $\begin{array}{c}\text { Mind maps and } \\
\text { self-effort helped } \\
\text { in understanding } \%\end{array}$ & $\begin{array}{c}\text { Difficult to } \\
\text { understand and } \\
\text { struggling } \%\end{array}$ & $\begin{array}{c}\text { Struggled and } \\
\text { had difficulties } \\
\text { but understood } \\
\text { in the end } \%\end{array}$ & $\begin{array}{l}\text { Did not find } \\
\text { the tutorials } \\
\text { helpful } \%\end{array}$ & $\begin{array}{c}\text { Non-category } \\
\text { and/or } \\
\text { miscellaneous \% }\end{array}$ & $\begin{array}{c}\text { No } \\
\text { response } \\
\%\end{array}$ \\
\hline 1 & 254 & 243 & 53.09 & 26.75 & 10.70 & 4.12 & 1.23 & 1.65 & 2.47 & 4.33 \\
\hline 2 & 254 & 238 & 53.78 & 29.83 & 6.30 & 3.78 & 2.10 & 1.26 & 2.94 & 6.30 \\
\hline 3 & 254 & 241 & 52.28 & 28.22 & 9.13 & 6.22 & 1.66 & 0.83 & 1.66 & 5.12 \\
\hline 4 & 254 & 229 & 53.71 & 33.19 & 5.68 & 3.06 & 1.31 & 1.31 & 1.75 & 9.84 \\
\hline 5 & 254 & 74 & 10.81 & 29.73 & 6.76 & 28.38 & 0.00 & 0.00 & 24.32 & 70.87 \\
\hline
\end{tabular}




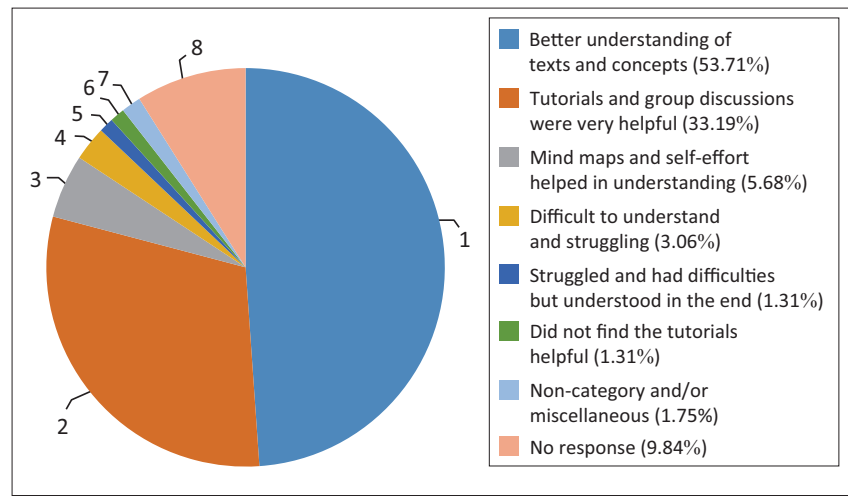

FIGURE 4: Student responses to Question 4 as percentages.

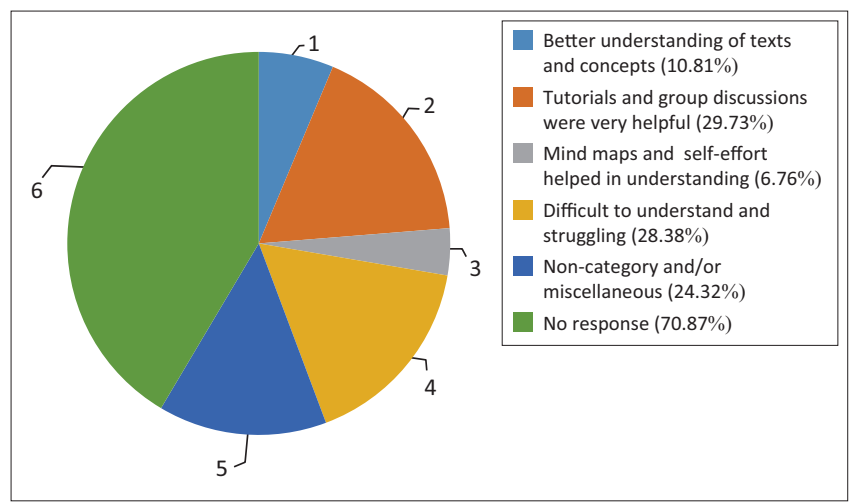

FIGURE 5: Students responses to Question 5 as percentages.

the texts to the real world. Others said that the intervention 'helped [them] grow as a reader and a student'. Less than $10 \%$ of respondents found they did not derive adequate benefit from the tutorials. Some of these students were negative towards sociology as a compulsory module, rather than the intervention itself, while other negative comments generally expressed frustration at the volume of reading that had to be done or the academic nature of the tutorials. With nearly $80 \%$ of all respondents reporting that the intervention had a positive outcome, we can conclude that, according to the students' reports, the intervention had a positive influence on improving students' reading of academic (sociology) texts, which had, until then, been a challenging task for the majority of them.

A similar trend was found in the responses to Questions 2, 3 and 4. In the responses to Question 2, ('Comment on and explain how the tutorials and the role-play reading activities assisted you in understanding sociology concepts'), 90\% of the students responded positively. In addition, more than half of the respondents reported that the tutorials helped to develop their understanding of texts. Some students said that the tutorials helped them put sociology concepts into their own words, which allowed them to grasp the meaning easily and helped them to remember the concepts better. Others also indicated that the group discussions meant that others offered examples of how the concepts worked in real life, which helped facilitate a deeper understanding of the concepts. A student who indicated that she was still struggling reported that, while the readings still seemed difficult, if she applied what had been taught in tutorials, she felt that she would have found it easier to engage with the concepts and the reading of the texts.

When asked in Question 3 how the tutorials and role-play activities assisted with writing sociology assignments, 90\% reported overwhelming success. Less than $1 \%$ of all respondents said that the tutorials did not help. Students frequently praised the tutors who helped them with structure and organisation. They also explained that the assignments were 'fun' as they felt confident in using their own ideas as well as the ideas generated by the debates that took place during tutorials. Some responses are given below:

'[The assignment] was fun to write and [it gave] a great platform to express opinions in answering the question. The debates in tutorials were also helpful.' (S1, female)

'[The assignment] was easy because we developed a sense of working together.' (S2, female)

'I was able to write more and faster because I understood.' (S3, male)

'This has been a challenge for me, but I am improving. The activities in tutorials are really helpful.' (S4, female)

Similar trends were found in the responses to Question 4, which required students to comment and explain how the intervention assisted them in writing the first semester sociology examination. A large number of students commented that they could recall relevant examples and ideas easily because these had been thoroughly discussed during tutorials. Others noted the value of doing the readings before the exam as it helped contextualise and reinforce the class content and tutorial activities. A slight downside to the responses is that a few students reported that they were still struggling and others indicated that the tutorials did not help, as they continued to struggle until the end. This may suggest that students who perceived the intervention negatively at first perhaps saw the value of the intervention at the end of the semester. It further suggests that intervention is a process and outcomes are gradual but eventually beneficial. Some students' responses to Question 4 are given below:

'It was difficult if you did not attend tutorials. Tutorials helped me a lot.' (S5, female)

'I gained a lot of knowledge that I used in the exam.' (S6, female)

'Tutorials helped me understand all the questions.' (S7, male)

'I was able to write a proper essay that earned me good marks. Eventually difficult ideas became clearer.' (S8, female)

In Question 5, students were asked to give additional comments. Unfortunately, $70 \%$ of students did not respond. However, the majority of the students who responded gave positive feedback. There were a few students who commented that they were still having some difficulty in reading their assigned texts. The specific comments included difficulty with understanding concepts, as well as the level of language and the length of the readings. Nevertheless, the majority 
commented that they had improved while others explained that the activities and discussions during tutorials had resulted in their forming a bond with their tutorial group members and the tutor, which encouraged them and enabled them to persevere in reading the assigned texts, to participate in class activities and to write assignments. This social aspect of reading seems to have played an important role in their motivation and reading development. According to research, social literacy develops motivation and contributes to reading improvement (Chinn, Anderson \& Waggoner 2001; McRae \& Guthrie 2009). Others commented that they had come to appreciate the ability to read and that the tutorials were a key factor in improving their reading proficiency. Others added that the intervention could be extended to include tutorial study groups during examination period:

'Tutorials are the best method of learning.' (S9, female)

'I would be failing if it wasn't for the tutorials.' (S10, female)

'The readings become interesting because of the discussions and applications to real life.' (S11, female)

'Sociology texts are easy to understand when one chooses to work on them.' (S12, male)

Considering the high percentage of students who responded positively to the intervention, who indicated that the intervention was helpful and that it helped them to improve in various ways, it can be concluded that the integrated approach to reading of subject-specific texts was successful. Students stated that the strategies they were taught and the role-play improved their reading, and to quote one of them, 'helped [us] grow as readers'. According to Hosseini et al. (2012) and other reading researchers, such as Guthrie (2008) and Anderson (2003:1), appropriate use of strategies enhances reading comprehension and ensures success in learning. The use of appropriate strategies enabled students to approach difficult and often complex texts in a way that demystified the texts. Scaffolding of the texts could also have contributed in making them easier to understand. The use of role-play made the students read their texts and they seemed to have done so with a positive attitude, as they wanted to perform their roles successfully. Parrott and Cherry (2011) found a similar motivation for the students in their study, as they read their text in order not to disappoint their peers during the role-play. According to Grabe and Stoller (2011) and Guthrie and Wigfield (2000), when students are motivated, they are willing to read even difficult texts and make an effort to understand them. Thus the students seemed to have applied deep reading in an effort to understand and be able to contribute to group discussions. This led to the majority of students reporting better understanding of texts and concepts. Robert and Robert (2008) and Parrott and Cherry (2011) found that when given reading responsibilities for group discussions, students did their reading in order not to disappoint the group. In addition, because of the discussions that ensued in the groups, more meaning and insights were given with regard to the texts by various students in the group, resulting in the majority of students understanding the texts better.
On the affective dimension, students reported that it was fun and enjoyable. These affective aspects contributed to increasing students' willingness to read and do so deeply. According to Grabe and Stoller (2011) and Guthrie (2008), high motivation and interest in addition to a positive attitude propel students to read and to read frequently to obtain the benefits thereof. It is therefore recommended that a reading intervention at tertiary level target the reading of subject-specific texts using an integrated approach to help improve students' comprehension of texts and concepts, as well as their affective reading levels.

\section{Conclusion}

Considering that a number of first-year students face challenges in reading, and in particular reading texts in their subject field because of inadequacies at school level, interventions have become necessary to help these students improve their reading of academic texts. An intervention was introduced to improve first-year sociology students' reading of sociology texts, which were dense, complex and contained many difficult concepts. The intervention focused on innovative techniques such as role-play and other activities that integrated cognitive and affective teaching techniques. Students worked in groups during tutorials and took on different roles when engaging with texts. Questionnaires completed by students after the 12-week intervention showed that the majority had benefited from the intervention. In relation to each question, seven themes were identified: (1) better understanding of concepts and the assigned reading materials; (2) the tutorials and group discussions were helpful; (3) mind maps, role-play and other strategies helped with understanding; (4) challenges and difficulties were experienced but understanding improved towards the end of the semester; (5) students still had difficulty with comprehension and were still facing huge challenges; (6) they did not find the tutorial helpful. Whereas less than 5\% reported challenges and difficulty even after the intervention, the majority (91\%) reported improvements in their reading as a result of the intervention. Therefore, combining affective and cognitive techniques with innovative activities helped to improve students' reading of academic texts that they had hitherto found very challenging.

Although students overwhelmingly agreed on the positive effect of the intervention techniques used in tutorials to improve their reading comprehension, no follow-up test was performed to confirm these positive outcomes. It would be beneficial for a follow-up study to include a pre- and posttest of students' reading comprehension in order to compare these with the results from the present survey.

\section{Acknowledgements}

The authors thank the students, tutors and lecturers of the Sociology Department for making this research possible. The research was supported by a Competitive Support for Unrated Researchers grant from the National Research Foundation. 


\section{Competing interests}

The author declares that they have no financial or personal relationships that may have inappropriately influenced them in writing this article.

\section{Authors' contribution}

N.A.Y.B. was responsible for conceptualising the title of the manuscript and collecting and analysing the data. M.M.L. was responsible for the introduction and presentation of data and graphs. Both authors were responsible for the literature review, methodology and discussion of findings.

\section{References}

Anderson, L.W., Krathwohl, D.R., Airasian, P.W., Cruikshank, K.A., Mayer, R.E., Pintrich, P.R. et al., 2001, A taxonomy for learning, teaching, and assessing: A revision of Bloom's Taxonomy of Educational Objectives, Pearson, Allyn \& Bacon, New York.

Anderson, N.J., 2003, 'Scrolling, clicking, and reading English: Online reading strategies in a second/foreign language', The Reading Matrix 3(3), 1-33.

Bandura, A., 1986, Social foundations of thought and action: A social cognitive theory, Prentice-Hall, Englewood Cliffs, NJ.

Bean, J.C., 2011, Engaging ideas: The professor's guide to integrating writing, critical thinking, and active learning in the classroom, 2nd edn., Wiley \& Sons, San Francisco, CA

Boakye, N., 2011, 'A multifaceted model for designing reading development programmes for L2 learners at tertiary level', Per Linguam 27(2), 111-128.

Boakye, N., 2012, 'A socio-affective approach to improving students' reading comprehension abilities', Unpublished PhD thesis, University of Pretoria, Pretoria.

Boakye, N., 2017a, 'Exploring students' reading profiles to guide a reading intervention', English Language Teaching 10(7), 158-174. https://doi.org/10.5539/elt.v10n7p158

Boakye, N., 2017b, 'Efficacy of a reading intervention for first-year university students', Per Linguam 33(1), 1-24.

Chinn, C.A., Anderson, R.C. \& Waggoner, M.A., 2001, 'Patterns of discourse in two kinds of literature discussion', Reading Research Quarterly 36(4), 378-411. https://doi.org/10.1598/RRQ.36.4.3

Department of Sociology, 2014, 'Students' examination results', Unpublished statistics, University of Pretoria, Pretoria.

Grabe, W. \& Stoller, F., 2011, Teaching and researching reading, Routledge, New York.

Guthrie, J.T., 2008, 'Reading motivation and engagement in middle and high school: Appraisal and intervention', in J.T. Guthrie (ed.), Engaging adolescents in reading, pp. 1-16, Corwin Press, Thousand Oaks, CA.

Guthrie, J.T. \& Wigfield, A., 2000, 'Engagement and motivation in reading', in M.L. Kamil, P.B. Mosenthal, P.D. Pearson \& R. Barr (eds.), Handbook of reading research, III, pp. 403-422, Lawrence Erlbaum, Mahwah, NJ.

Hidi, S. \& Anderson, V., 1992, 'Situational interest and its impact on reading and expository writing', in A. Renninger, S. Hidi \& A. Krapp (eds.), The role of interest in learning and development, pp. 215-237, Lawrence Erlbaum, Hillsdale, MI.
Hosseini, E., Khodaei, F.B., Sarfallah, S. \& Dolatabadi, H.R., 2012, 'Exploring the relationship between critical thinking, reading comprehension and reading relationship between critical thinking, reading comprehension and reading
strategies of English university students', World Applied Sciences Journal 17(10), strategies of

Howie, S.J., Combrinck, C., Roux, K., Tshele, M., Mokoena, G.M. \& McLeod Palane, N., 2017, PIRLS literacy 2016: South African highlights report, Centre for Evaluation and Assessment, Pretoria.

Hsieh, H.-F. \& Shannon, S.E., 2005, 'Three approaches to qualitative content analysis', Qualitative Health Research 15(9), 1277-1288.

McKenna, M.C., 2001, 'Development of reading attitudes', in L. Verhoeven \& C. Snow (eds.), Literacy and motivation: Reading engagement in individuals and group, $\mathrm{pp}$ 135-176, Lawrence Erlbaum, Mahwah, NJ.

McRae, A. \& Guthrie, J.T., 2009, 'Promoting reasons for reading: Teacher practices that impact motivation', in E.H. Hiebert (ed.), Reading more, reading better, pp. 55-76, Guilford Press, New York, viewed n.d., from http://www.readingrockets.org/ article/teacher-practices-impact-reading-motivation

Morgan, D.L., 1993, 'Qualitative content analysis: A guide to paths not taken', Qualitative Health Research 1, 112-121.

Parrott, H.M. \& Cherry, E., 2011, 'Using structured reading groups to facilitate deep learning', Teaching Sociology 39(4), 354-370. https://doi.org/10.1177/0092055X 11418687

Pretorius, E.J., 2000, 'Reading and the Unisa student: Is academic performance related to reading ability?', Progressio 22(2), 35-48.

Pretorius, E.J., 2002, 'Reading ability and academic performance in South Africa: Are we fiddling while Rome is burning?', Language Matters: Studies in the Languages of Southern Africa 33(1), 169-196. https://doi.org/10.1080/1022 8190208566183

Pretorius, E.J., 2007, 'Looking into the seeds of time: Developing academic literacy in high poverty schools', Ensovoort 11(2), 105-125.

Pretorius, E.J. \& Klapwijk, N.M., 2016, 'Reading comprehension in South African schools: Are teachers getting it, and getting it right?', Per Linguam 32(1), 1-20.

Pretorius, E.J. \& Lephalala, M., 2011, 'Reading comprehension in high-poverty schools: How should it be taught and how well does it work?', Per Linguam 27(2), $1-24$.

Roberts, J.C. \& Roberts, K.A., 2008, 'Deep reading, cost/benefit, and the construction of meaning: Enhancing reading comprehension and deep learning in sociology courses', Teaching Sociology 36(2), 125-140. https://doi.org/10.1177/0092055X 0803600203

Schiefele, U., Krapp, A. \& Winteler, A., 1992, 'Interest as a predictor of academic achievement: A meta-analysis of research', in K.A. Renninger, S. Hidi \& A. Krapp (eds.), The role of interest in learning and development, pp. 183-212, Lawrence Erlbaum, Hillsdale, NJ.

Taylor, S. \& Yu, D., 2009, 'Socio-economic status and educational achievement: Does education provide a stepping stone out of poverty in South Africa?', in J. Hofmeyr (ed.), Transformation Audit, pp. 66-75, Institute for Justice and Reconciliation, (ed.), Transfor
Cape Town.

Van Staden, S. \& Bosker, R., 2014, 'Factors that affect South African reading literacy achievement: Evidence from prePIRLS 2011', South African Journal of Education 34(3), 1-9. https://doi.org/10.15700/201409161059

Zimmerman, L., 2014, 'Lessons learnt: Observation of Grade 4 reading comprehension teaching in South African schools across the Progress in International Reading Literacy Study (PIRLS) 2006 achievement spectrum', Reading \& Writing 5(1), 1-9.

Zimmerman, L. \& Smit, B., 2014, 'Profiling classroom reading comprehension development practices from the PIRLS 2006 in South Africa', South African Journa of Education 34(3), 1-9. https://doi.org/10.15700/201409161101 